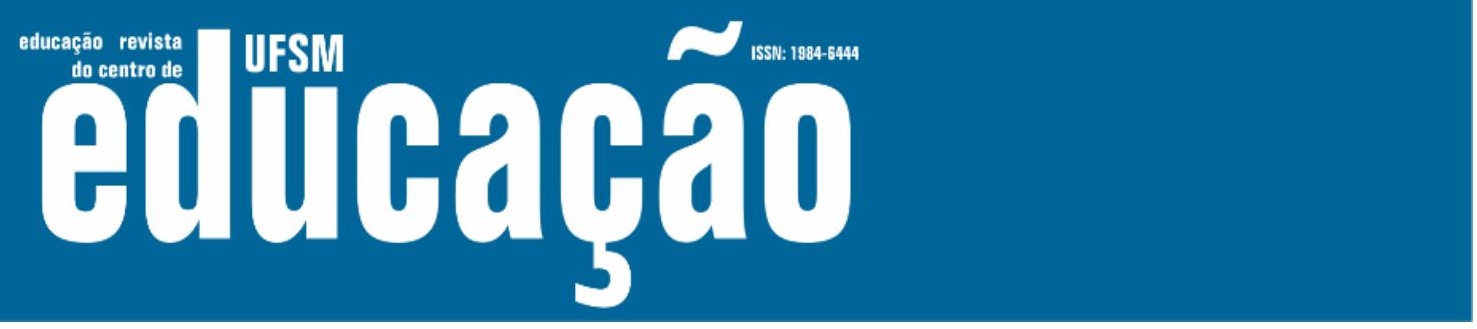

ISSN: 1984-6444 | http://dx.doi.org/10.5902/1984644443035

\title{
Mapeamento das medidas de exigibilidade coletiva para garantia do direito à educação infantil no Paraná
}

\author{
Mapping of collective enforcement procedures to guarantee the right to \\ early childhood education in the state of Paraná
}

Adriana Aparecida Dragone Silveira

Professora Doutora na Universidade Federal do Paraná. Curitiba, Paraná, Brasil. adrianadragone@yahoo.com.br - http://orcid.org/0000-0001-6022-627X

Barbara Cristina Hanauer Taporosky

Doutoranda na Universidade Federal do Paraná. Curitiba, Paraná, Brasil. barbara86ha@yahoo.com.br - http://orcid.org/0000-0002-8251-6005

\author{
Marina Feldman \\ Doutoranda na Rutgers University. New Jersey, Estados Unidos da América. \\ marina.feldman@rutgers.edu - http://orcid.org/0000-0002-6459-099X \\ Lusiane Gonçalves \\ Professora na rede de educação da Prefeitura Municipal de Curitiba. Curitiba, Paraná, Brasil. \\ lusianef@gmail.com - http://orcid.org/0000-0003-3233-2213
}

Recebido em 20 de março de 2020

Aprovado em 14 de dezembro de 2020

Publicado em 04 de setembro de 2021

\section{RESUMO}

Nos últimos anos tem crescido o envolvimento do sistema de justiça para a exigibilidade do direito à educação, entendido como judicialização da educação. $A$ literatura do campo tem discutido a ampliação desse fenômeno, relacionado a uma convergência de fatores, como a crescente juridificação da educação, o fortalecimento e a ampliação de instituições como o Ministério Público e a insuficiência das políticas públicas. Considerando estes fatores, o presente artigo objetiva apresentar e analisar um mapeamento das medidas de exigibilidade coletivas judiciais e extrajudiciais para garantia do direito à Educação Infantil no estado do Paraná, buscando identificar possíveis fatores explicativos para esse fenômeno em tal contexto. Para a concretização de tal objetivo, foram analisadas 71 medidas de exigibilidade em 60 municípios, localizadas no sistema de justiça do estado, no período entre 2005 e 2016. Os dados sobre os procedimentos coletivos foram cotejados com o perfil dos municípios de acordo com seu porte, faixa de rendimento médio e taxa de urbanização. Ainda foi analisada a relação da existência de procedimentos com variáveis institucionais do sistema de justiça e taxas de atendimento em creche e préescola. Conclui-se que, no Paraná, a requisição coletiva do direito à Educação Infantil 


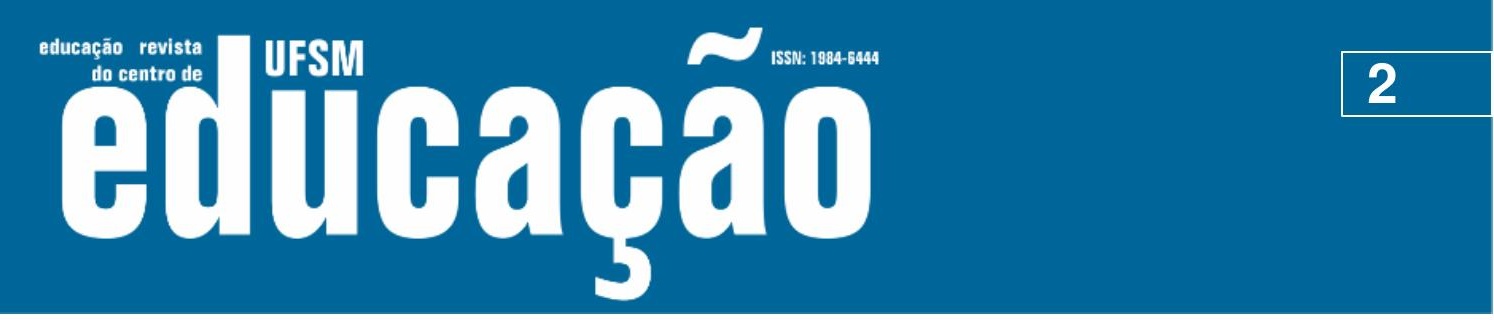

ISSN: 1984-6444 | http://dx.doi.org/10.5902/1984644443035

tem se dado exclusivamente por iniciativa do Ministério Público, possuindo uma forte relação com suas variáveis institucionais, com maior incidência em municípios não tão pequenos, com maior taxa de urbanização e renda média.

Palavras-chave: Direito à educação; Educação Infantil; Judicialização.

\section{ABSTRACT}

In the last years, there has been an increase in the involvement of the justice system in the enforcement of the right to education, understood as the judicialization of education. The literature in the field has been discussing the intensification of this phenomenon, relating it to a conjunction of factors, such as the increasing juridification of education, the strengthening and expansion of institutions like the Public Prosecution's Office, and the insufficiency of public policies. Considering these factors, this article aims to present and analyze a mapping of judicial and extrajudicial collective procedures to enforce the right to Early Childhood Education in the state of Paraná, seeking to identity possible explanatory factor to the phenomenon in this context. To achieve such a goal, 71 enforcement procedure from 60 municipalities, located in the state justice system between 2005 and 2016, were analyzed. The data on collective procedures was collated with the characteristics of the municipalities, such as population size, range of median income, and urbanization rate. The existence of a procedure was also analyzed in relation with the justice system's institutional variables and the enrollment rates in early preschool and pre-Kindergarten. The conclusion is that, in the state of Paraná, the collective demand for the right to Early Childhood Education has been happening exclusively through the initiative of the Public Prosecution's Office, having a strong relation with its institutional variables, and a higher incidence in municipalities that are not as small, with higher urbanization rates, and higher median incomes.

Keywords: Right to education; Early Childhood Education; Judicialization

\section{Introdução}

O atendimento educacional de crianças pequenas no Brasil tem apresentado crescimento, com ampliação dos números de matrículas em instituições de Educação Infantil (EI) nos últimos anos. Porém, o esforço do poder público para a oferta deste direito continua insuficiente para atender a população de 0 a 5 anos em creches e préescolas, em especial quando são consideradas as discrepâncias de atendimento entre parcelas da população por critérios sociais, raciais e de localidade (ROSEMBERG, 1996; BRASIL, 2018). 


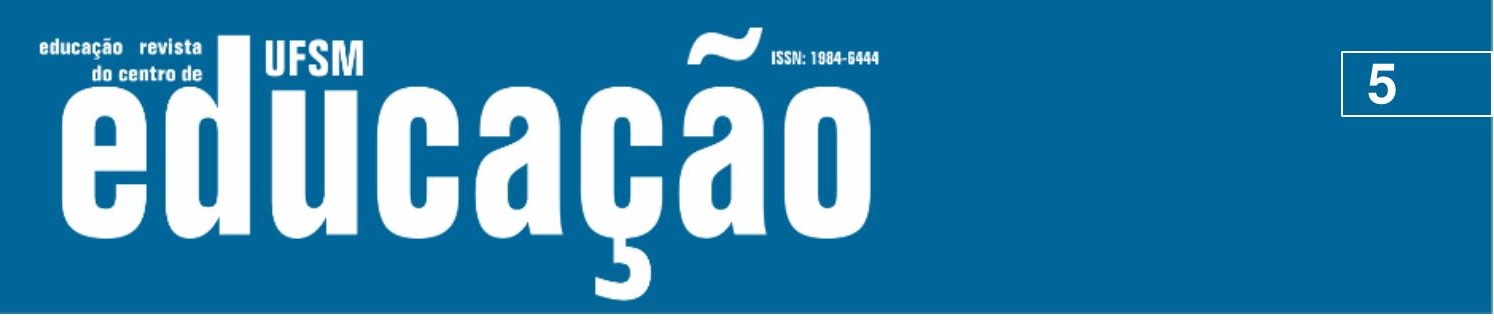

ISSN: 1984-6444 | http://dx.doi.org/10.5902/1984644443035

atuação relativa à exigibilidade do direito à educação nos últimos anos (DAMASCO, 2008; RIZZI; XIMENES, 2010; ARANTES, 2011; OLIVEIRA, 2011; SILVEIRA, 2006, 2014, 2018). Na Constituição Federal de 1988 (CF/88), esta instituição teve sua autonomia consagrada como promotora do acesso à justiça no cenário da redemocratização do país (ARANTES, 1999; SOUSA SANTOS, 2007). A atuação dos promotores de justiça para garantia do direito à educação também foi fortalecida no art. 201 do Estatuto da Criança e do Adolescente de 1990 (ECA/90). A responsabilidade do MP de exigir o direito à educação perante o poder público, para cumprimento da obrigatoriedade do acesso à educação, é também reiterada no art. $5^{\circ}$ da Lei de Diretrizes e Bases da Educação Nacional de 1996 (LDB/96). Institucionalmente, se mostra relevante o parecer do ano de 2015, emitido por órgão colegiado do MP, afirmando a centralidade de uma atuação direcionada à exigibilidade do direito à EI (BRASIL, 2015).

Considerando-se tal cenário, o artigo aborda inicialmente uma breve justificativa do enfoque em medidas de cunho coletivo. Em seguida, apresenta-se descrição dos procedimentos metodológicos, bem como uma contextualização da atuação do MP na área da educação no Paraná. Apresenta-se, então, o cenário geral dos procedimentos no estado, seguido das análises em que tais procedimentos foram cotejados com o perfil dos municípios, variáveis institucionais do sistema de justiça e faixas de atendimento na El. Por fim, discutem-se considerações finais que apontam para a relevância de variáveis institucionais como fator explicativo para a judicialização da El, por meio de medidas coletivas.

\section{Judicialização coletiva da educação infantil}

A judicialização da educação, e especificamente da El, tem ocorrido pelo reconhecimento desta primeira etapa da educação básica como um direito social desde a CF/88. Mais além, a CF/88 também prevê instrumentos jurídicos e instituições responsáveis pela garantia dos direitos, seja em âmbito individual ou coletivo. Com isso, amplia-se a possibilidade de exigibilidade para além do atendimento individual, havendo judicialização que incide no processo de formulação e de implementação de 


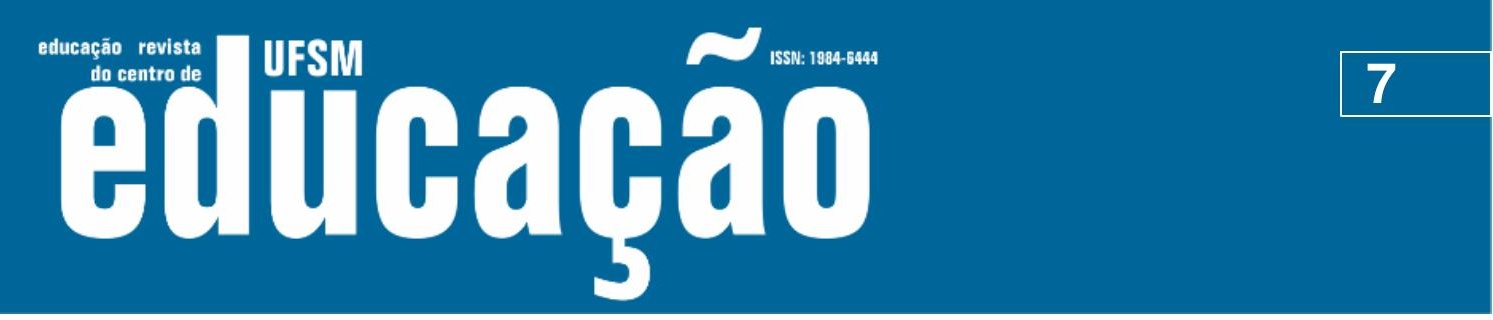

ISSN: 1984-6444 | http://dx.doi.org/10.5902/1984644443035

\section{Procedimentos metodológicos para coleta e organização dos dados}

Visando levantar os procedimentos coletivos de exigibilidade do direito à El no estado do Paraná, foram utilizadas duas frentes de busca: uma judicial e outra extrajudicial. O levantamento judicial pretendia identificar, no Tribunal de Justiça do Estado do Paraná (TJ-PR), ações coletivas para garantia do direito à El, por meio de decisões proferidas no período compreendido entre 2005 e 2016². O recorte temporal leva em consideração o julgamento pelo Supremo Tribunal Federal que, no ano de 2005, reconheceu a El como dever do Estado, reafirmando sua justiciabilidade. Compreende-se que após esta data há uma maior abertura do Poder Judiciário para o reconhecimento do direito, dado o posicionamento da corte máxima do país. A escolha deste período de análise também se deu pela existência do projeto estratégico do MP paranaense, executado entre 2011 e 2016 para a expansão de vagas na El.

O levantamento tomou em consideração apenas aqueles pedidos em ações coletivas para os quais já havia decisão proferida e disponível na base de dados do Tribunal de Justiça do estado em questão. Não é possível afirmar que todas as decisões sobre o tema foram encontradas, uma vez que alguns tribunais não disponibilizam, por exemplo, decisões em processo em segredo de justiça. Desta forma, o resultado da presente pesquisa se refere aos casos com decisões proferidas e que foram disponibilizados pelos tribunais por meio destas ferramentas.

Para tal levantamento, inicialmente utilizaram-se dados obtidos em pesquisa anterior realizada por Silveira (2018). Na sequência, foi realizada busca no sistema de jurisprudência do TJ-PR, em seu sítio eletrônico, por meio dos descritores "creche", "pré-escola" e "educação infantil". Realizou-se a leitura de todas as ementas das decisões encontradas, selecionando-se as que possuíam proximidade com o objeto da presente pesquisa. A seguir, foi realizada a leitura da íntegra das decisões previamente selecionadas, tornando possível excluir as que se referiam a outros temas que não a $\mathrm{El}$, aquelas proferidas em demandas individuais, ações coletivas que beneficiavam um número limitado de crianças (de 1 a 12 crianças), decisões 


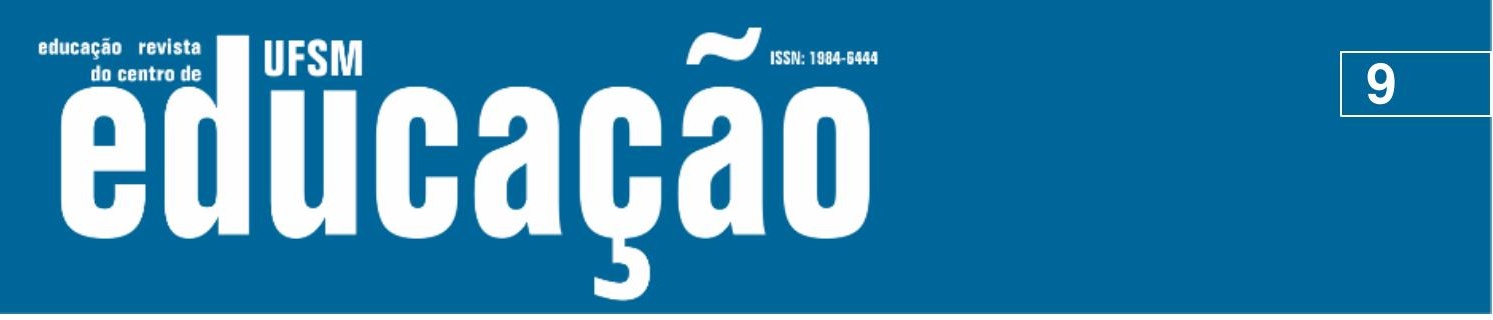

ISSN: 1984-6444 | http://dx.doi.org/10.5902/1984644443035

\section{A atuação do Ministério Público para a garantia do direito à Educação Infantil no Paraná}

$\mathrm{Na}$ análise do caso paranaense ressalta-se que a única instituição responsável por procedimentos coletivos de exigibilidade do direito à El é o MP. A centralidade de tal instituição já havia sido evidenciada anteriormente por Silveira (2018), que levantou a existência de pedidos na esfera judicial relacionados à El. Em tal análise, a grande maioria havia sido ingressada pelo MP, sendo todos os pedidos coletivos atribuídos a tal instituição. Na presente pesquisa, pode-se agregar a tal constatação a existência de ampla atuação do MP também pela via extrajudicial.

A centralidade do MP paranaense nas temáticas afeitas ao direito à El se relaciona à atuação do Caopcae/Educação ${ }^{3}$, que buscou incidir nesta área por meio de projeto estratégico executado entre 2011 e 20164. Tal projeto, denominado "Atuação do Ministério Público do Estado do Paraná para a criação de vagas em Educação Infantil", começou a ser discutido pelo Caopcae/Educação no ano de 2009, sendo lançado em 2011, por meio da "Campanha 100\% creche e pré-escola para todos".

Segundo Silveira (2018), a priorização da El na atuação do MP paranaense iniciou-se no ano de 2009, durante as discussões para a elaboração do projeto estratégico da instituição. A proposta de atuação, por meio do Caopcae/Educação, em prol da universalização da El pode ser atribuída a três fatores: 1) as demandas que chegavam ao conhecimento do MP, por meio das distintas Promotorias de Justiça; 2) a previsão da ampliação do acesso à El no Plano Nacional de Educação de 2001; e 3) o interesse nesta área por parte da promotora de justiça que coordenava o Caopcae/Educação na época, que tinha a El como objeto de estudo acadêmico. A aprovação da EC 59/2009, durante o período de elaboração do plano estratégico do MP, foi incorporada posteriormente como justificativa adicional para esta atuação.

O projeto do MP orientou os promotores de justiça com roteiros e modelos de procedimentos para acompanhar a oferta de vagas na El, especialmente para as crianças de 4 e 5 anos, visando unificar e potencializar o trabalho, especificando informações a serem obtidas e cuidados a serem tomados na execução do projeto 


\section{T usm

ISSN: 1984-6444 | http://dx.doi.org/10.5902/1984644443035

estratégico. Os promotores de justiça receberam um levantamento estatístico sobre a população estimada ( 0 a 3 anos / 4 e 5 anos), dados de matrícula em creche e préescola e o déficit (número absoluto e percentual) de cada um dos municípios paranaenses nos anos de 2012 e $2014^{5}$ (SILVEIRA, 2018).

As orientações incluíram modelos de ofício ao prefeito, aos vereadores e aos conselheiros tutelares para informar sobre a existência do procedimento do MP. Também foi incluído modelo de requisição de informações acerca do planejamento municipal para implementação progressiva de vagas na El para todas as crianças de 4 e 5 anos de idade do município até o início do ano letivo de 2016. Mais além, foi enviada minuta de TAC, sugerindo modelo de acordo extrajudicial a ser firmado com a prefeitura para ampliação de vagas na etapa. Os promotores de justiça foram, ainda, orientados - caso não houvesse possibilidade de firmar um TAC - a ajuizar uma Ação Civil Pública (ACP) (SILVEIRA, 2018).

\section{Cenários de exigibilidade coletiva da EI no Paraná}

Após a análise dos documentos levantados, identificou-se a existência de 71 medidas de exigibilidade coletiva, sendo 40 extrajudiciais (TACs) e 31 judiciais (ações propostas perante o Poder Judiciário e julgadas pelo TJ-PR). Embora o recorte temporal da presente pesquisa se inicie no ano de 2005, identificaram-se TACs apenas a partir do ano de 2008 e decisões judiciais em ações coletivas apenas a partir do ano de 2011. Os procedimentos se distribuíram temporalmente da seguinte forma: 


\section{Aillbapẫ}

ISSN: 1984-6444 | http://dx.doi.org/10.5902/1984644443035

Gráfico 1- Distribuição temporal das medidas de exigibilidade coletiva para ampliação de vagas na EI (2008 - 2016)

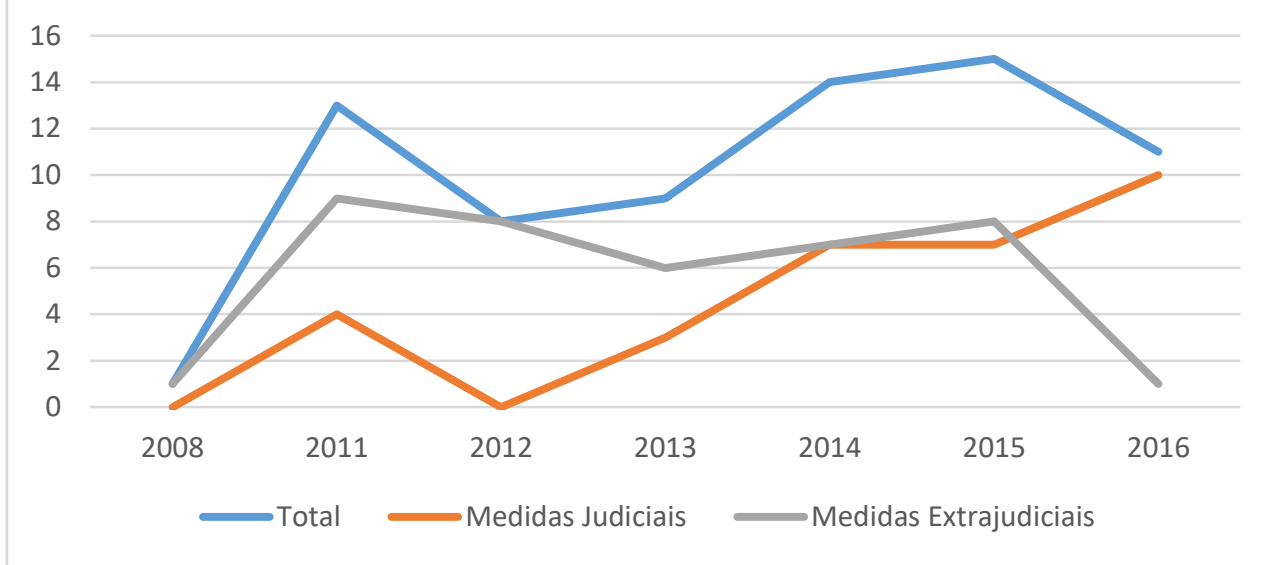

Fonte: Elaborado a partir de Subplan (2016) e TJ-PR (2016).

Percebe-se que os dois momentos com maior quantidade de TACs firmados correspondem ao ano de lançamento do projeto estratégico do MP e ao que antecede seu prazo de finalização, mesmo ano do prazo de cumprimento da EC 59/2009. Quanto às medidas judiciais, é possível observar que as primeiras decisões aparecem no ano de 2011, havendo crescimento ou manutenção do número de ações entre 2012 e 2016. Vale dizer que 2016 é o ano com maior número de decisões, mesmo tendo sido analisadas apenas aquelas proferidas até o mês de julho deste ano, indicando uma ampliação deste tipo de demanda.

Percebe-se, ainda, um aumento no número de ações judiciais por parte do MP no decurso do tempo e uma redução das estratégias extrajudiciais - ou seja, o firmamento de TACs. Há duas hipóteses explicativas para o fenômeno: uma primeira, de que o MP tenha passado a envidar maiores esforços no ajuizamento de medidas judiciais, possivelmente pela proximidade do prazo de cumprimento da EC 59/2009; e uma segunda, de que boa parte das medidas judiciais mais recentes tenha sido ajuizada em períodos próximos ao firmamento dos TACs, mas que as decisões só foram proferidas posteriormente, tendo em vista que há um trâmite processual desde o ajuizamento do processo em primeira instância até que a ação chegue ao julgamento do TJ-PR. 


\section{N-T

ISSN: 1984-6444 | http://dx.doi.org/10.5902/1984644443035

Ao analisar-se a distribuição geoespacial das medidas, ou seja, os municípios nos quais se identificaram a existência de medidas, quer judiciais, quer extrajudiciais, identificaram-se municípios em que mais de uma medida havia sido proposta. Os procedimentos localizados encontram-se distribuídos em 60 municípios paranaenses. Portanto, embora tenham sido localizadas 71 medidas, as mesmas vinculam-se a 60 municípios. A distribuição geoespacial não se mostra uniforme nas regiões do estado, havendo maior concentração na região oeste e norte do estado e na Região Metropolitana de Curitiba (RMC).

Há comarcas no estado onde se observa a concentração de procedimentos extrajudiciais, o que em alguns casos está relacionado ao firmamento de mais de um TAC pelo mesmo promotor de justiça, em diferentes municípios de sua comarca (SILVEIRA, 2018). Também interessa indicar a existência de municípios com uso reiterado de estratégias extrajudiciais, como no caso de Telêmaco Borba (FELDMAN, SILVEIRA, 2019), e municípios com uso de diferentes estratégias, como no caso de Araucária, no qual também aparece uma concentração de pedidos judiciais individuais (SILVA, 2016), ou o de Rio Branco do Sul, com o firmamento de um TAC e, posteriormente, a necessidade da execução judicial do acordo mediante ajuizamento de uma ação. Por fim, vale destacar o caso do município de Colombo, com muitas medidas judiciais coletivas, que são utilizadas pelo MP como estratégia para a proteção de direitos individuais ${ }^{6}$ (GONÇALVES, 2017). 


\section{Uism Autlatato

\section{Perfil dos municípios com existências de medidas coletivas para a ampliação do atendimento em Educação Infantil}

Sendo constatado que a distribuição das medidas de exigibilidade coletiva do direito à EI não se dá de modo uniforme ou atinge todas as regiões do estado, buscase compreender o perfil dos municípios atingidos pelo fenômeno da judicialização por meio das seguintes variáveis: porte municipal, faixa de rendimento médio e taxa de urbanização. A análise toma em conta, portanto, a quantidade de municípios que possuem procedimentos no estado - 60 municípios - e não a quantidade de procedimentos encontrados -71 procedimentos.

Quando analisada a existência de procedimentos coletivos por portes populacionais ${ }^{8}$, observa-se maior concentração de procedimentos em municípios de Pequeno Porte 1, seguido dos municípios de Pequeno Porte 2, o que indica que o fenômeno tem se dado, no Estado, predominantemente em municípios menores, de até 100.000 habitantes (GRÁFICO 3). Entretanto, analisando-se proporcionalmente a quantidade de municípios no estado, de acordo com os portes populacionais, percebese uma representatividade significativa dos municípios de Pequeno Porte 2, Médio Porte e Grande Porte entre aqueles com procedimentos coletivos. Nos municípios de Pequeno Porte 2, por exemplo, que representam 55 municípios no Paraná, localizamos 17 com procedimentos coletivos, ou 30,9\% dos municípios deste porte populacional. No caso dos municípios de Médio Porte podemos perceber um percentual alto, de $50 \%$ dos municípios com procedimento coletivo, enquanto nos de Grande Porte o percentual é de $38,8 \%$. Desse modo, apesar da grande quantidade de procedimentos, uma parcela menor dos municípios de Pequeno Porte 1 foi atingida pelo fenômeno, representando apenas $9,3 \%$ do total de municípios nesta categoria. 


\section{$\sim$ ussm,

ISSN: 1984-6444 | http://dx.doi.org/10.5902/1984644443035

Gráfico 3 - Número de municípios por porte populacional no total do estado e entre aqueles com procedimentos coletivos, Paraná (2008-2016)

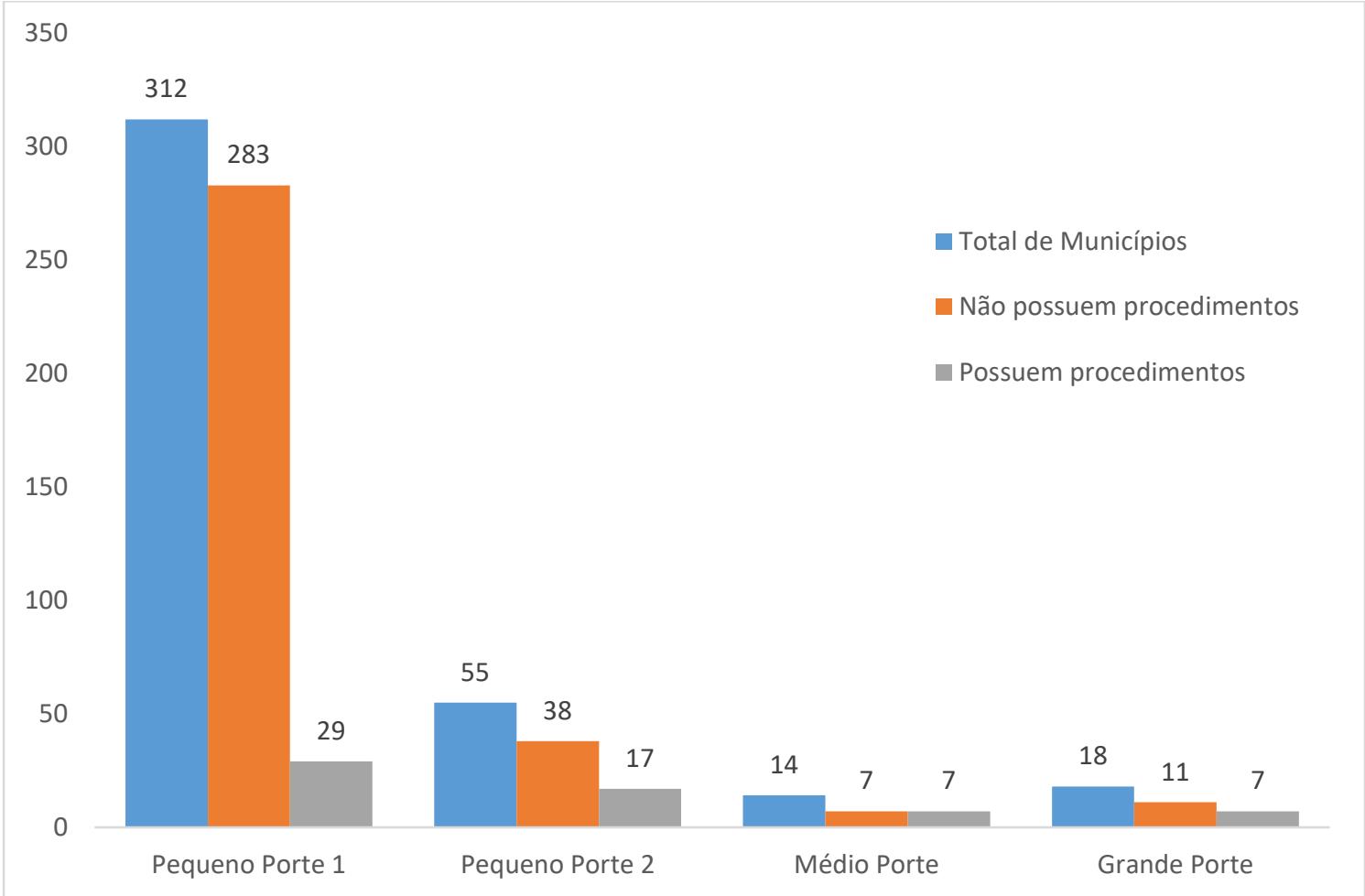

Fonte: Organizado a partir dos dados da pesquisa e dados de porte populacional do IBGE (2010).

Já quando considerado o rendimento médio da população (GRÁFICO 4), observa-se que há uma incidência significativa de procedimentos nos municípios localizados na faixa entre um e dois salários mínimos, atingindo 19,6\% dos municípios nessa faixa. Já nos municípios de menor faixa de rendimento, há menor quantidade e incidência, sendo que, proporcionalmente, apenas $9,6 \%$ desses municípios foram atingidos por algum procedimento coletivo. 


\section{TH Usw

ISSN: 1984-6444 | http://dx.doi.org/10.5902/1984644443035

Gráfico 4 - Número de municípios por faixa de rendimento médio no total do estado e entre aqueles com procedimentos coletivos Paraná, 2005-2016

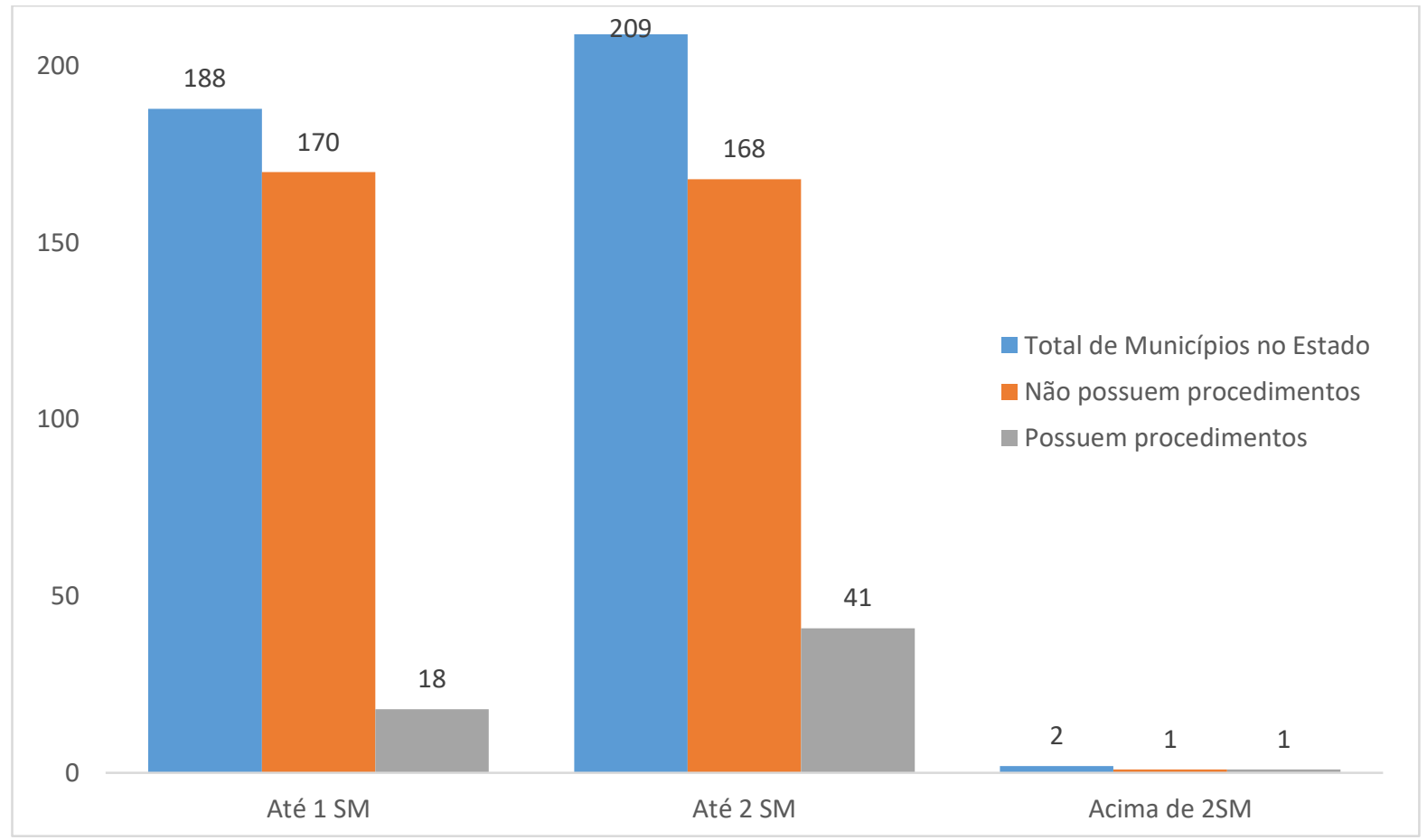

Fonte: Organizado a partir dos dados da pesquisa e dados da faixa de rendimento médio do IBGE (2010).

Por fim, considera-se o cruzamento entre a existência de tais medidas e a taxa de urbanização dos municípios paranaenses (GRÁFICO 5). No Paraná, 44\% dos municípios têm mais de $76 \%$ de taxa de urbanização e é neste grupo de municípios que se encontra a maior incidência de medidas. Foram localizadas medidas coletivas em 22,03\% dos municípios que integram tal faixa de urbanização. Já nos municípios com menor urbanização, a incidência deste tipo de procedimento é menor. Como se pode observar no gráfico acima, nos municípios com até $25 \%$ de urbanização não há sequer uma medida coletiva, sendo que estas ocorrem em apenas 12,5\% dos municípios na segunda faixa, e $9 \%$ dos municípios da terceira faixa. 


\section{$\sim$ ussm,

ISSN: 1984-6444 | http://dx.doi.org/10.5902/1984644443035

Gráfico 5 - Número de municípios por faixas de urbanização no total do estado e entre aqueles com procedimentos coletivos, Paraná, 2005-2016

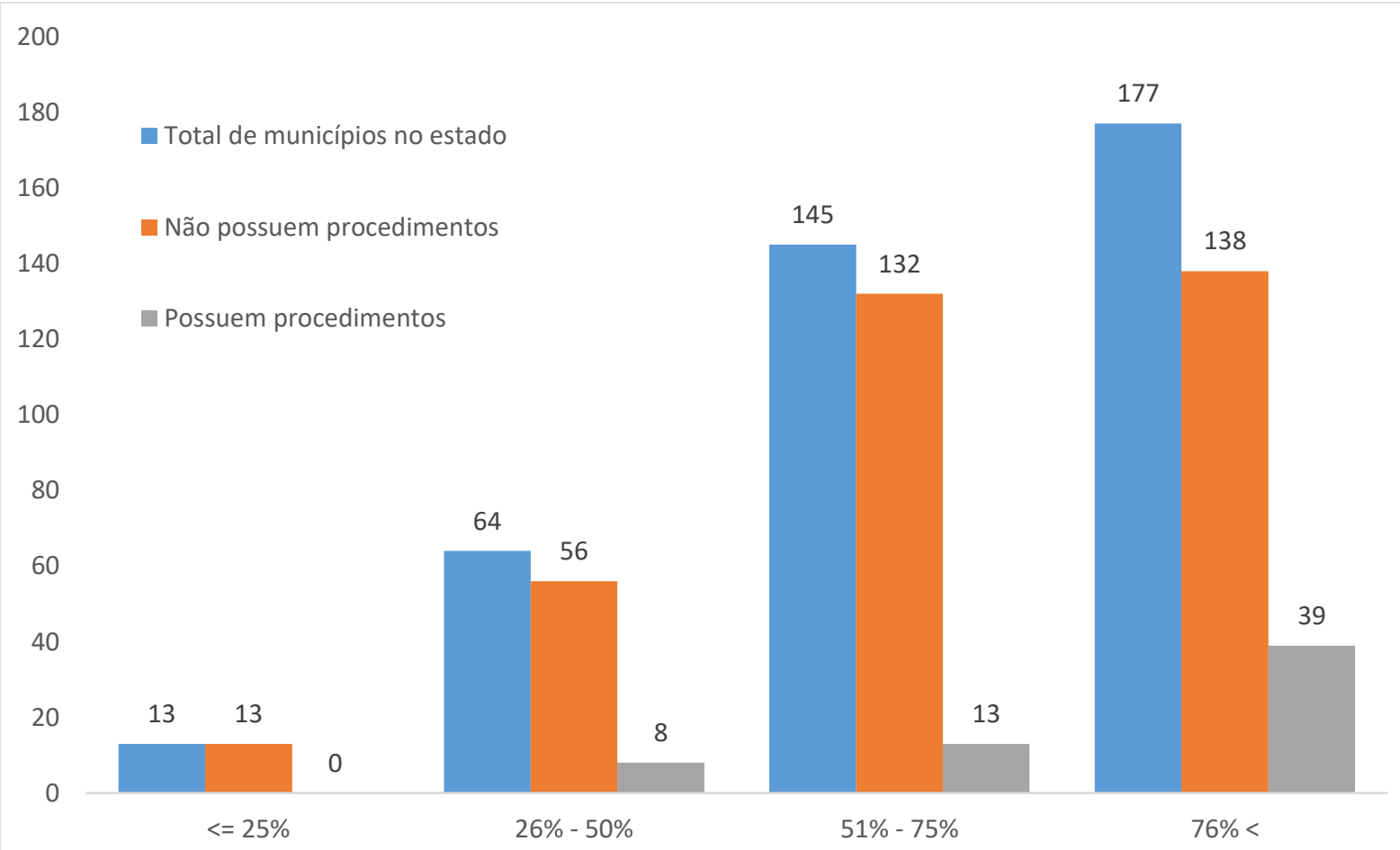

Fonte: Organizado a partir dos dados da pesquisa e dados da taxa de urbanização do IBGE (2010)

Tal concentração de medidas em municípios mais urbanizados pode ser entendida como reflexo tanto de maior procura da população por instituições de El, quanto de maior acesso ao sistema de justiça. Ambas as possibilidades poderão ser mais bem avaliadas ao observar as variáveis relativas ao sistema de justiça e o do MP nos municípios, bem como aquelas variáveis referentes ao atendimento educacional na etapa. Por hora, pode-se afirmar que a presença de medidas coletivas judiciais ou extrajudiciais demonstra certa relação direta com a taxa de urbanização dos municípios, havendo maior incidência proporcional em municípios de médio porte, ainda que uma maior quantidade de medidas ocorra em municípios pequenos, que representam maioria no estado. Ainda, pode-se indicar uma concentração de tais procedimentos em municípios com rendimento médio acima de um salário mínimo. 


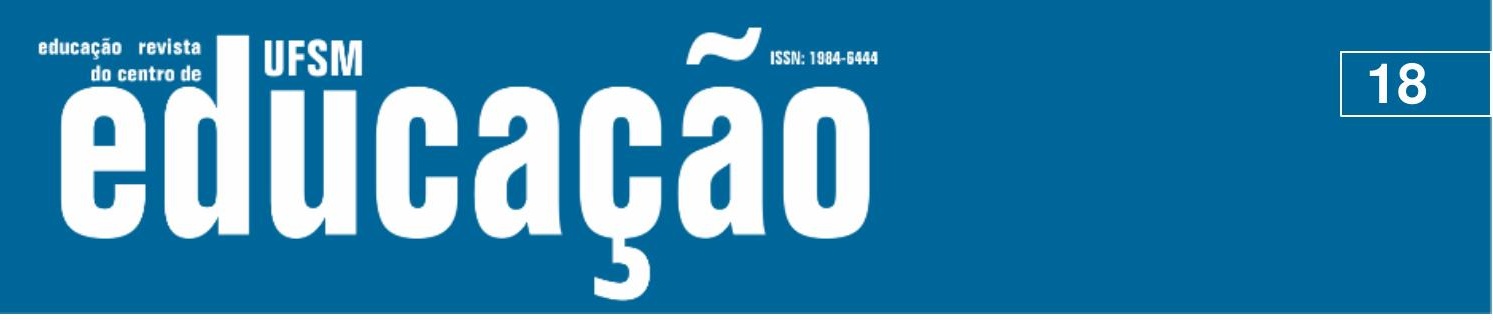

ISSN: 1984-6444 | http://dx.doi.org/10.5902/1984644443035

\section{Procedimentos coletivos, possíveis condicionantes institucionais do sistema de justiça e taxas de atendimento}

Para além dos indicadores municipais que demonstram o perfil dos municípios atingidos pelo fenômeno analisado, busca-se analisar outros fatores que podem estar relacionados à existência de medidas coletivas. Tais variáveis, apresentadas nessa seção, encontram-se divididas entre as variáveis referentes ao sistema de justiça nos municípios e aquelas referentes ao atendimento na El. Tal escolha se justifica pela hipótese de que possíveis fatores explicativos para a exigibilidade do direito à El por meio do sistema de justiça sejam, por um lado, a demanda organizada da população em havendo carência de atendimento e, por outro, a capacidade de mobilização dos atores do sistema de justiça para levar tais demandas adiante.

No que se refere ao sistema de justiça no município, analisa-se aqui a característica de ser ou não sede de comarca, o tipo de entrância da comarca e o nível de especialização da promotoria de justiça responsável. Em alguns casos analisa-se por tipos de procedimentos, enquanto em outros se olha apenas para a existência de medida, seja judicial ou extrajudicial.

Quanto a primeira variável, vale dizer que municípios que não são sede de comarca não contam com serviços judiciários na localidade - ou seja, não há promotores e/ou juízes no município. Portanto, a população necessita deslocar-se ao município sede da Comarca em busca de serviços (PARANÁ, 2003), tal sendo o caso da maioria significativa dos municípios no Paraná. Ainda assim, $68 \%$ dos municípios com medidas coletivas são sedes de comarcas, mostrando uma maior incidência em municípios com tal característica (GRÁFICO 6). Já entre os municípios que não são sede de comarca, que são tendencialmente menores, apenas um percentual de 8,8\% possui medida coletiva, enquanto o mesmo cálculo para as sedes de comarca nos leva a um percentual de 22,5\%. Dos 19 municípios que não são sede de comarca, mas possuem procedimentos, em 10 há procedimentos também no município sede de comarca. $O$ dado pode indicar que promotores de justiça estejam empenhando maiores esforços na sua localidade de trabalho, embora haja outros municípios em seu âmbito de competência territorial. 


\section{Tusm 2

ISSN: 1984-6444 | http://dx.doi.org/10.5902/1984644443035

Gráfico 6 - Número de municípios pela característica de ser ou não sede de comarca, no total do estado e entre aqueles com procedimentos coletivos, Paraná, 2008-2016

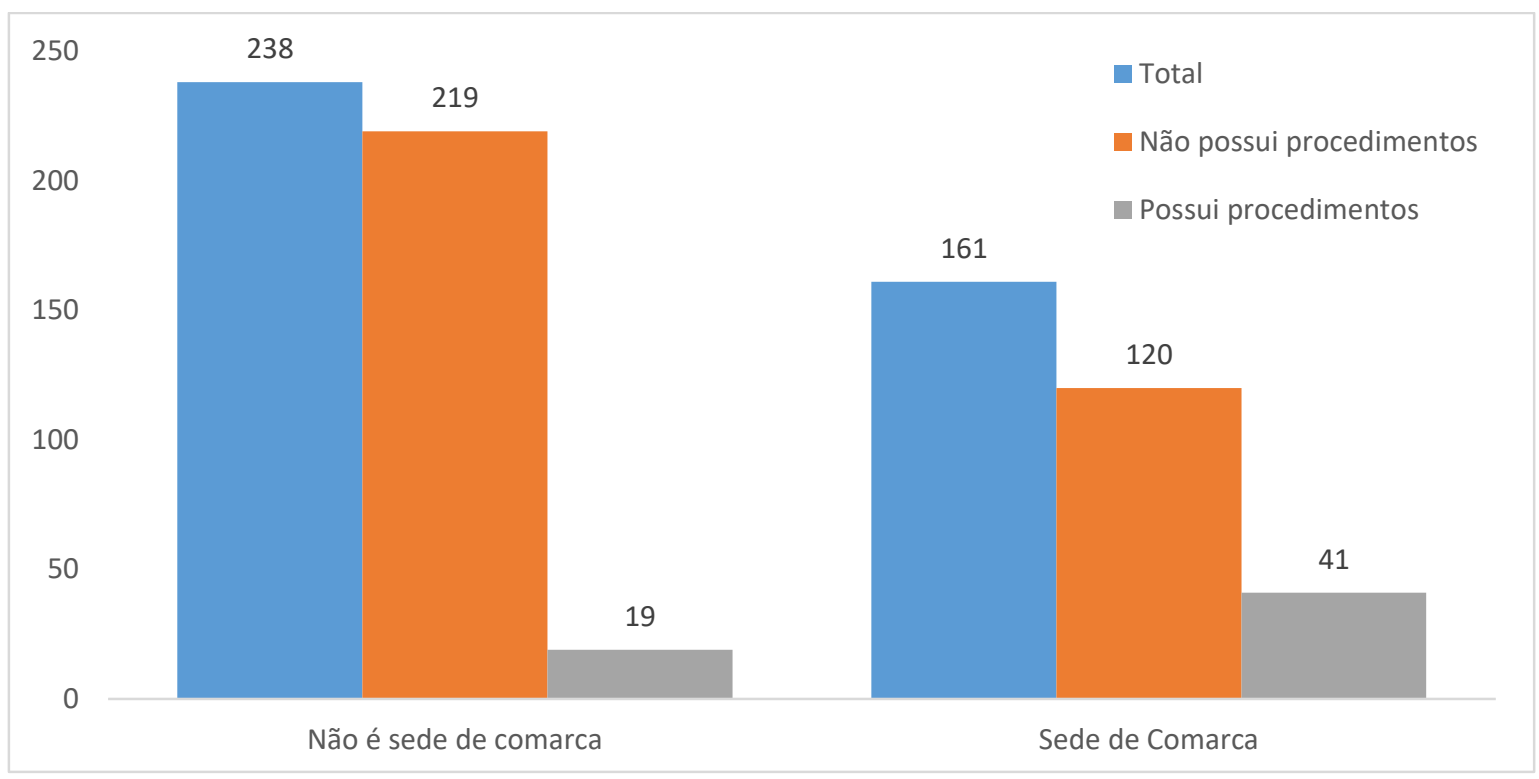

Fonte: Organizado a partir dos dados da pesquisa.

Quando tal dado é detalhado segundo tipo de procedimento, percebe-se que a concentração em municípios que são sede de comarca é mais significativa no caso das medidas judiciais (GRÁFICO 7). Quanto aos TACs, ainda que também se concentrem em municípios com tal característica, há uma parcela significativa em municípios que não são sede de comarca. 


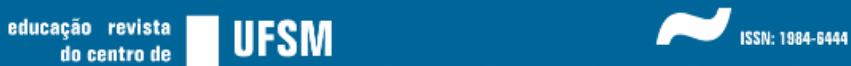

ISSN: 1984-6444 | http://dx.doi.org/10.5902/1984644443035

Gráfico 7 - Distribuição dos procedimentos por municípios segundo característica de ser ou não sede de comarca

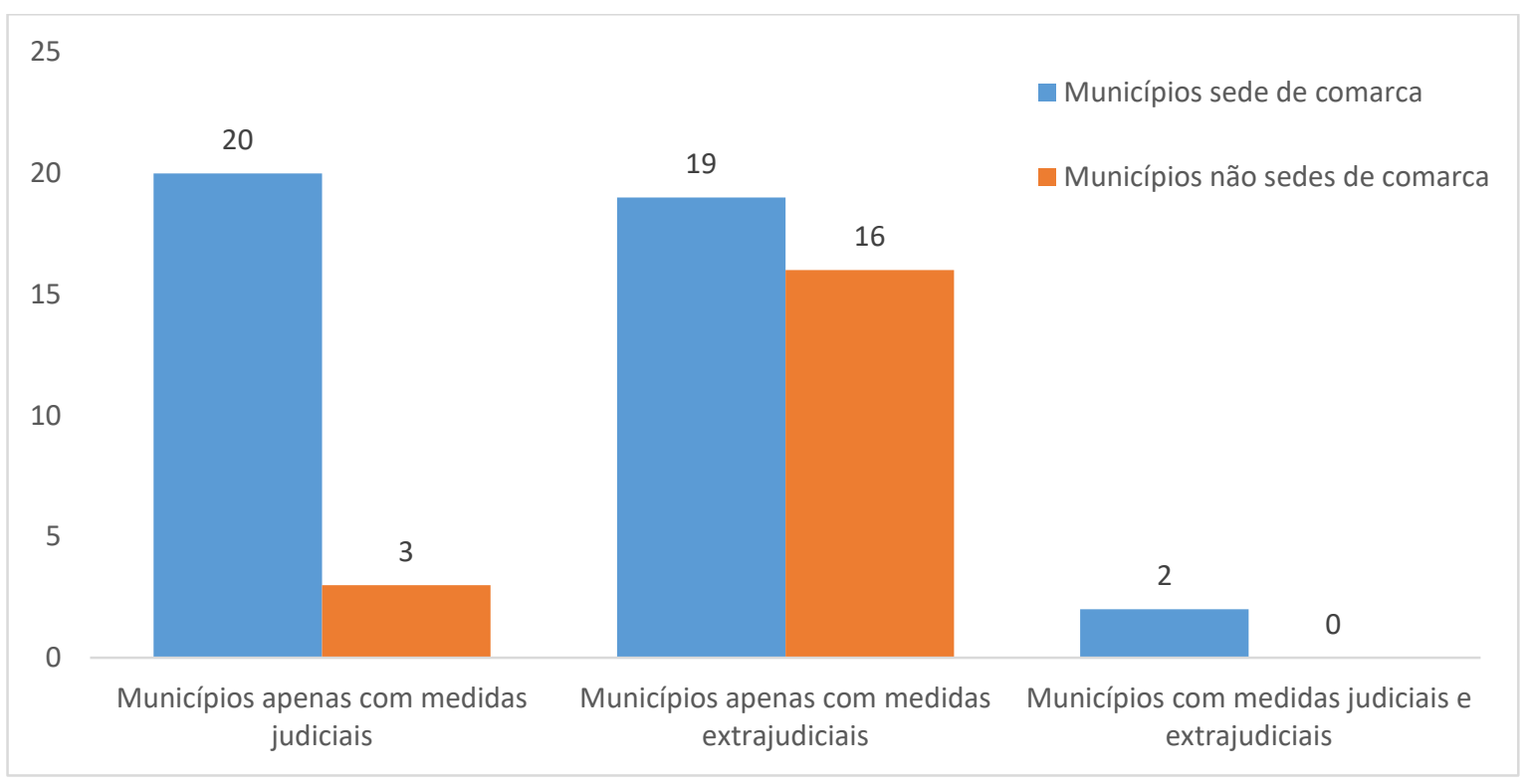

Fonte: Organizado a partir dos dados da pesquisa

Os dados apresentados no gráfico acima podem indicar que a presença de um promotor de justiça alocado no município tenha menor centralidade para o firmamento de um acordo extrajudicial do que no caso de uma ação coletiva judicial. Também se relaciona a tal dado o fato de que, em pelo menos três comarcas, um mesmo promotor tenha firmado dois ou mais TACs, sendo um deles no município sede de sua comarca e o restante em outros municípios. Outro possível fator explicativo estaria na relação mais próxima entre promotoria de justiça e poder executivo em municípios de pequeno porte (SILVA, 2001), o que potencializaria o firmamento de acordos extrajudiciais.

Na sequência, analisa-se a existência de procedimentos coletivos por entrância da comarca à qual os municípios estão vinculados (GRÁFICO 8). Comarcas de entrância inicial compõem-se de um único juízo ou vara, com competência genérica, enquanto as comarcas de entrância intermediária e final compõem-se de duas ou mais varas, já especializadas em relação às competências de julgamento (PARANÁ, 2003). 


\section{T-1 usm,

ISSN: 1984-6444 | http://dx.doi.org/10.5902/1984644443035

Gráfico 8 - Número de municípios pela entrância da comarca, entre aqueles com procedimentos coletivos, Paraná, 2008-2016910

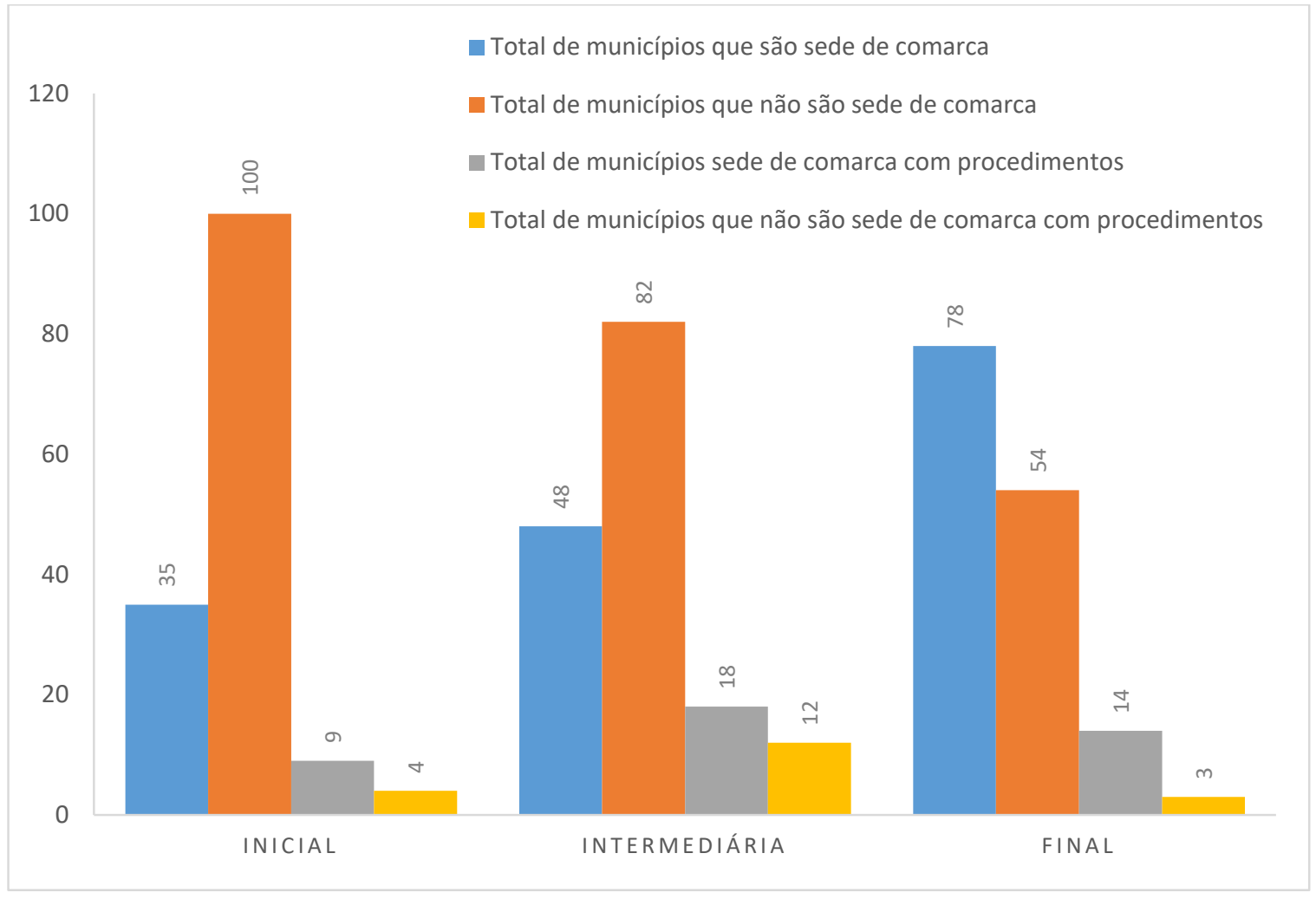

Fonte: Organizado a partir dos dados da pesquisa (2008-2016).

Quando se analisa a existência de procedimentos coletivos por entrância da comarca ${ }^{11}$, observa-se uma maior quantidade de municípios com procedimentos entre aqueles de entrância intermediária. Ao analisarem-se as comarcas de entrância final, percebe-se que das 35 existentes no estado, em 14 há municípios com procedimentos. Desta forma, percebe-se que, proporcionalmente, a maior incidência ocorre nestas, o que pode estar relacionado à maior disponibilidade de promotores de justiça, com maior especialização e dividindo suas atribuições com outros pares. Como as comarcas de entrância inicial contam geralmente com um único promotor de justiça responsável por todas as matérias de direito, a atenção às necessidades da população residente na localidade em relação à El é dividida com outras demandas, o que corrobora a existência de relação entre variáveis institucionais do MP e medidas coletivas de exigibilidade do direito à educação. 


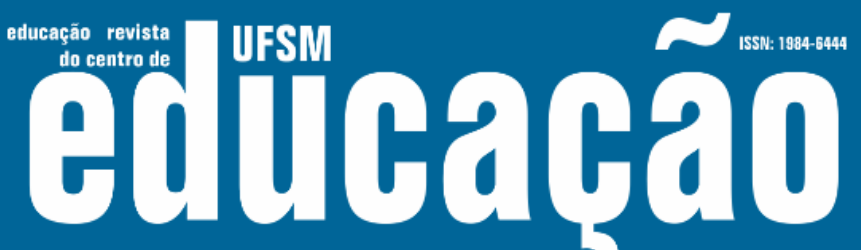

ISSN: 1984-6444 | http://dx.doi.org/10.5902/1984644443035

No entanto, quando se busca observar a mesma questão por meio da análise das áreas de especialização das promotorias de justiça proponentes das medidas, percebe-se que não há um padrão (GRÁFICO 9). Tal observação não invalida a explicação apresentada acima, pois se sabe que em entrâncias intermediárias e finais há maior quantidade de promotorias, com divisão de atribuições; porém, percebe-se que a área de especialização da promotoria não aparece como fator determinante. $\mathrm{Na}$ maior parte dos municípios analisados, a educação se encontra diluída no conjunto de outras áreas de atuação do promotor de justiça. Para além da atuação nas áreas de família, infância e juventude e registros públicos paralelamente à educação, vemos comarcas em que não há registro das áreas de especialização das promotorias ou as mesmas contam, ainda, com outras matérias do direito em suas atribuições. Aliandose estes dados com o fato de que a maior quantidade de procedimentos se dá em municípios de Porte Populacional 1, percebe-se que, no Paraná, a maioria dos procedimentos parecem ocorrer em comarcas menores e menos especializadas, apesar da incidência proporcionalmente maior em comarcas de entrância final.

Para a elaboração de tal análise, foram consideradas as comarcas em que existem promotorias específicas de educação, infância e juventude e aquelas comarcas nas quais a competência das causas relacionadas ao direito à educação é acumulada com matérias atinentes ao direito de família e infância e juventude ou, ainda, registros públicos. Caso a promotoria acumulasse outras competências além destas, considerou-se que a mesma não possuía especialização, ante a especificidade da análise ora realizada. 


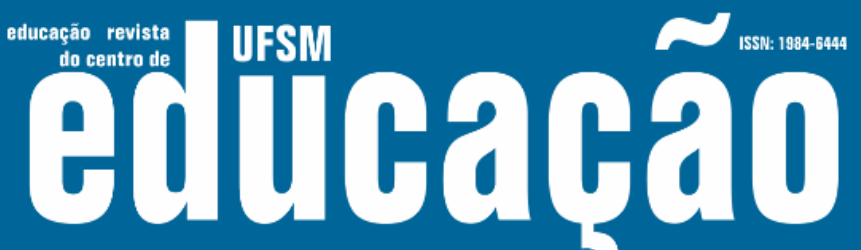

ISSN: 1984-6444 | http://dx.doi.org/10.5902/1984644443035

Gráfico 9 - Comarcas com procedimento, segundo especialização da promotoria de justiça responsável, Paraná, 2008-2016

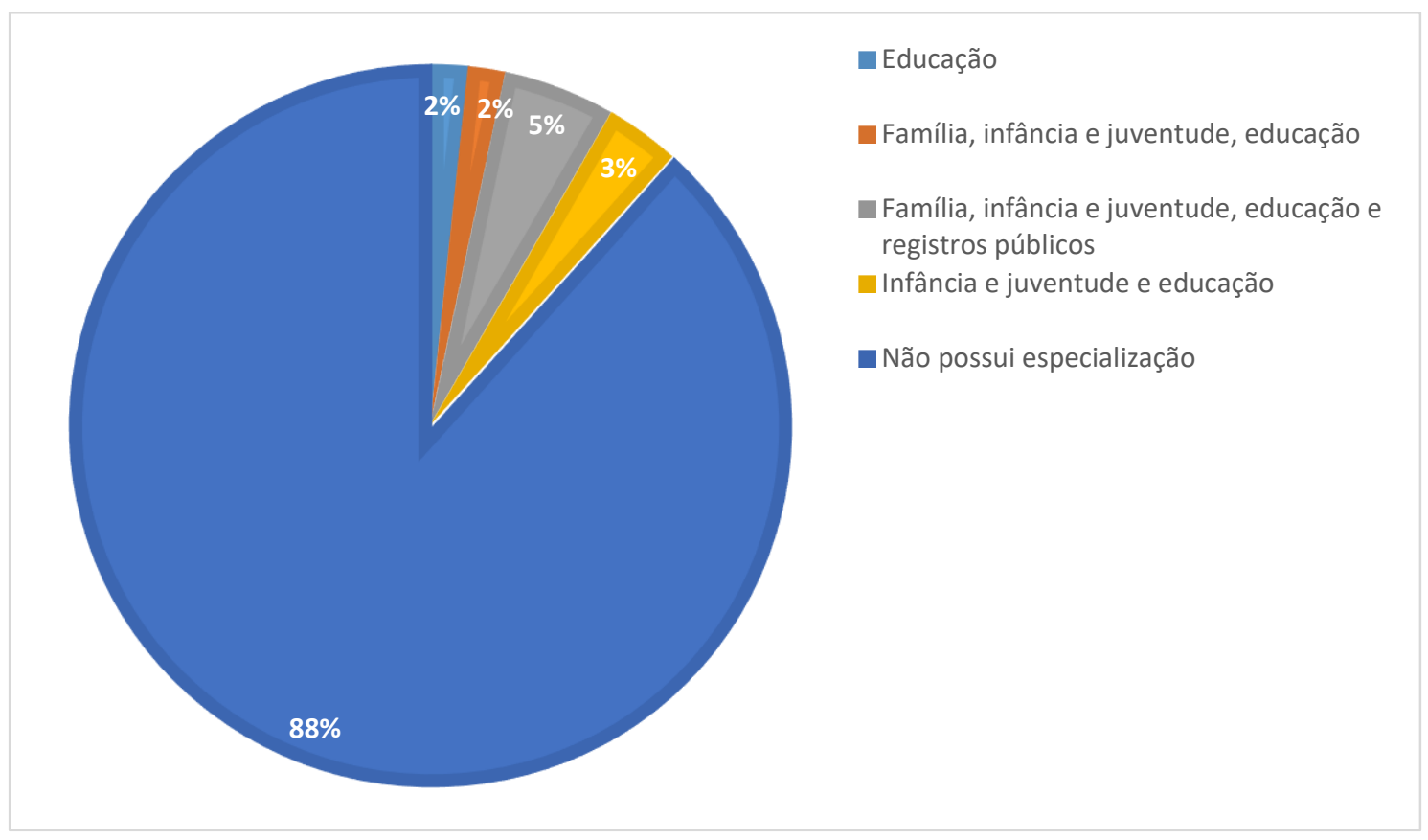

Fonte: Organizado a partir dos dados da pesquisa (2008-2016).

Em síntese, por mais que os dados referentes à especialização das promotorias sejam pouco conclusivos, vemos a incidência de procedimentos em municípios que são sede de comarca e, portanto, possuem promotores alocados na localidade. Mais além, nas comarcas de entrâncias intermediária e final, há uma maior concentração de procedimentos, o que pode estar relacionado à maior quantidade de promotores alocados na localidade, dividindo atribuições referentes às diferentes áreas. Assim, parece corroborada a vertente explicativa da existência de medidas coletivas que diz respeito à capacidade de mobilização dos atores do sistema de justiça em levar adiante demandas da população. Resta analisar a vertente que diz respeito à carência de atendimento.

Nesse sentido, foi cotejada a existência de medidas coletivas com as faixas de atendimento na El em 2010 nos municípios paranaenses. Percebe-se que para as quatro menores faixas, que vão até $33,169 \%$ de atendimento, o percentual de municípios que possuem procedimentos é um pouco mais significativo do que entre $o$ 


\section{Aillbapẫ \\ 3}

ISSN: 1984-6444 | http://dx.doi.org/10.5902/1984644443035

total de municípios no estado. O estado do Paraná conta com 399 municípios, dos quais 203 encontram-se nestas quatro faixas, representando 50,9\% dos municípios no estado, enquanto representam $60 \%$ dos municípios com medidas coletivas para exigibilidade da El - ou seja, 36 municípios dentre os 60 que possuem medidas.

Portanto, apenas $40 \%$ dos municípios com procedimento encontram-se nas faixas mais altas de atendimento (acima de 33,169\%), enquanto 49,1\% dos municípios do estado encontram-se nessa faixa. A exceção parece se encontrar na faixa de atendimento mais alta, na qual se encontram apenas dois municípios no estado, sendo que em um deles há procedimento. Em todo caso, percebe-se uma relação, de modo geral, entre o baixo atendimento e a existência de medidas coletivas.

Gráfico 10 - Número de municípios por faixa de taxa de atendimento em El (2010), no total do estado e entre aqueles com procedimentos coletivos, Paraná, 2018

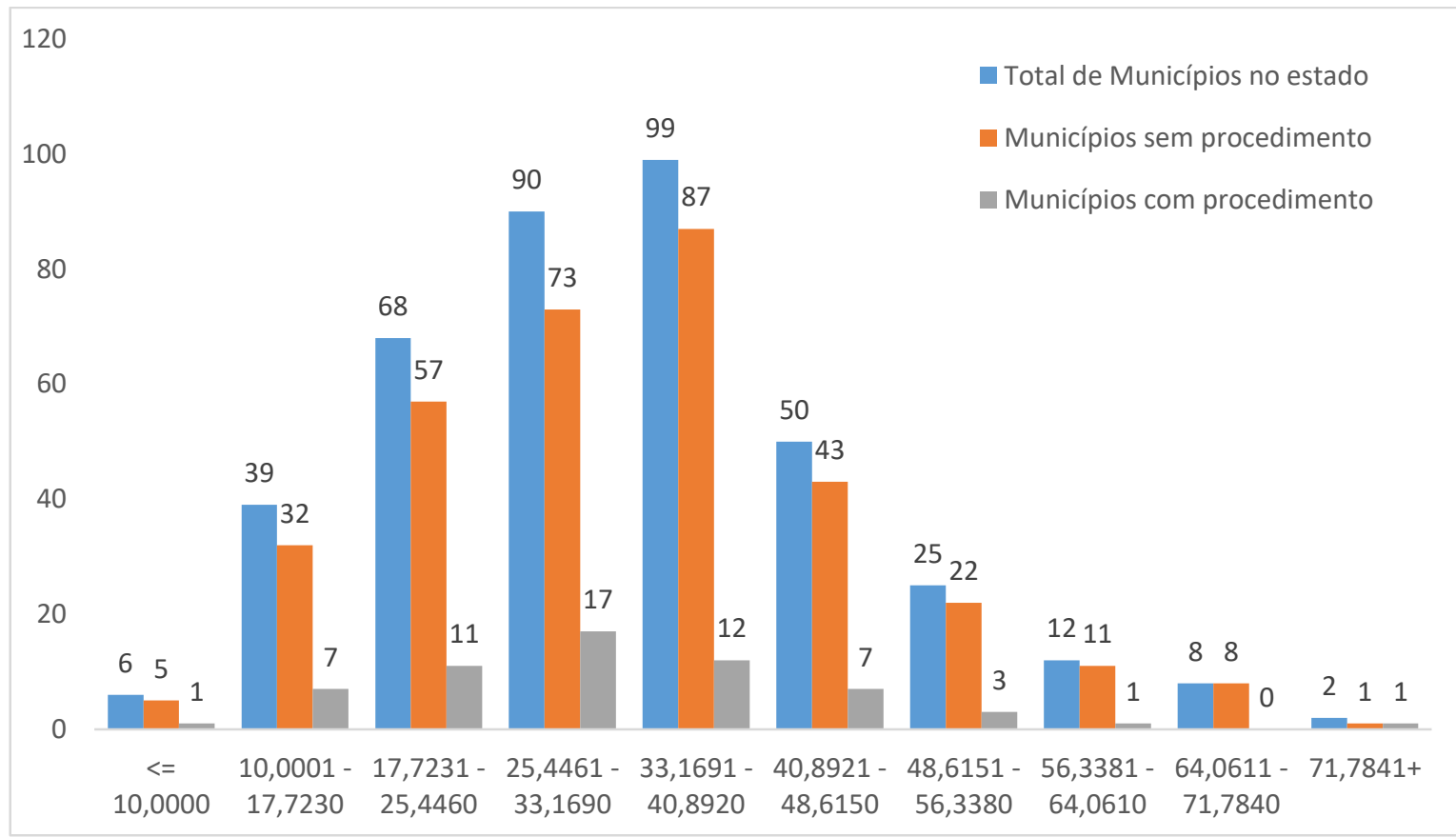

Fonte: Organizado a partir a partir dos dados da pesquisa, microdados do Censo escolar (Banco de matrículas, 2010) e dados populacionais Censo IBGE (2010).

Quando esta análise é realizada desmembrando-se o atendimento por creche e pré-escola, não se percebe o mesmo tipo de relação, o que também pode estar relacionado às problemáticas existentes no lançamento deste tipo de dados 


\section{Usm

ISSN: 1984-6444 | http://dx.doi.org/10.5902/1984644443035

(ROSEMBERG, 2015), corroboradas na análise do caso de Telêmaco Borba, por exemplo (FELDMAN; SILVEIRA, 2018). Em todo caso, analisam-se tais dados para avaliar se as relações observadas no âmbito geral da etapa se repetem.

No caso da creche (GRÁFICO 11), percebe-se que não há um padrão. Ainda que a maior parte dos procedimentos se concentre em municípios nas quatro menores faixas de atendimento, tais faixas concentram a grande maioria dos municípios no estado. Repetindo-se o procedimento feito acima para as quatro menores faixas de atendimento, percebe-se que representam $81,9 \%$ do total de municípios - ou seja, dos 399 municípios, 327 encontram-se nestas faixas de atendimento - enquanto são 90,1\% dos municípios com procedimentos - 54 dos 60 municípios que compõem o universo da análise.

Gráfico 11 - Número de municípios por faixa de taxa de atendimento em creche (2010), no total do estado e entre aqueles com procedimentos coletivos, Paraná, 2010

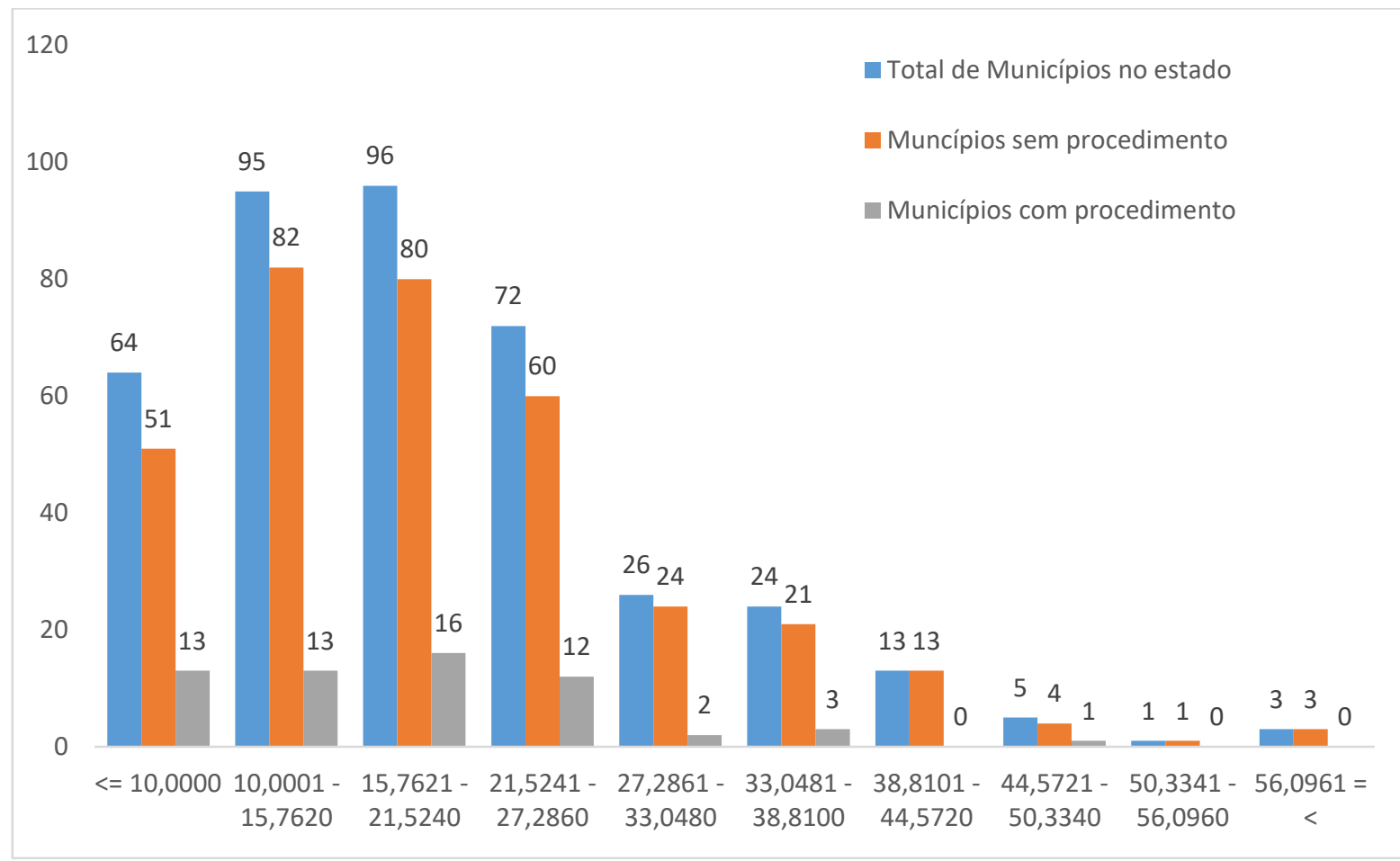

Fonte: Organizado a partir a partir dos dados da pesquisa, microdados do Censo escolar (Banco de matrículas, 2010) e dados populacionais Censo IBGE (2010). 


\section{Aillbapẫ \\ 3}

ISSN: 1984-6444 | http://dx.doi.org/10.5902/1984644443035

Já quando se observa o atendimento na pré-escola (GRÁFICO 12), também não parece haver padrão, bem como uma representatividade significativa das faixas com menor atendimento quando analisadas em conjunto. Observamos que as faixas com maior concentração de procedimentos são aquelas entre $35,55 \%$ e $61,11 \%$, que também são as faixas mais representativas na totalidade do estado.

Gráfico 12- Número de municípios por faixa de taxa de atendimento em pré-escola, no total do estado e entre aqueles com procedimentos coletivos, Paraná, 2010

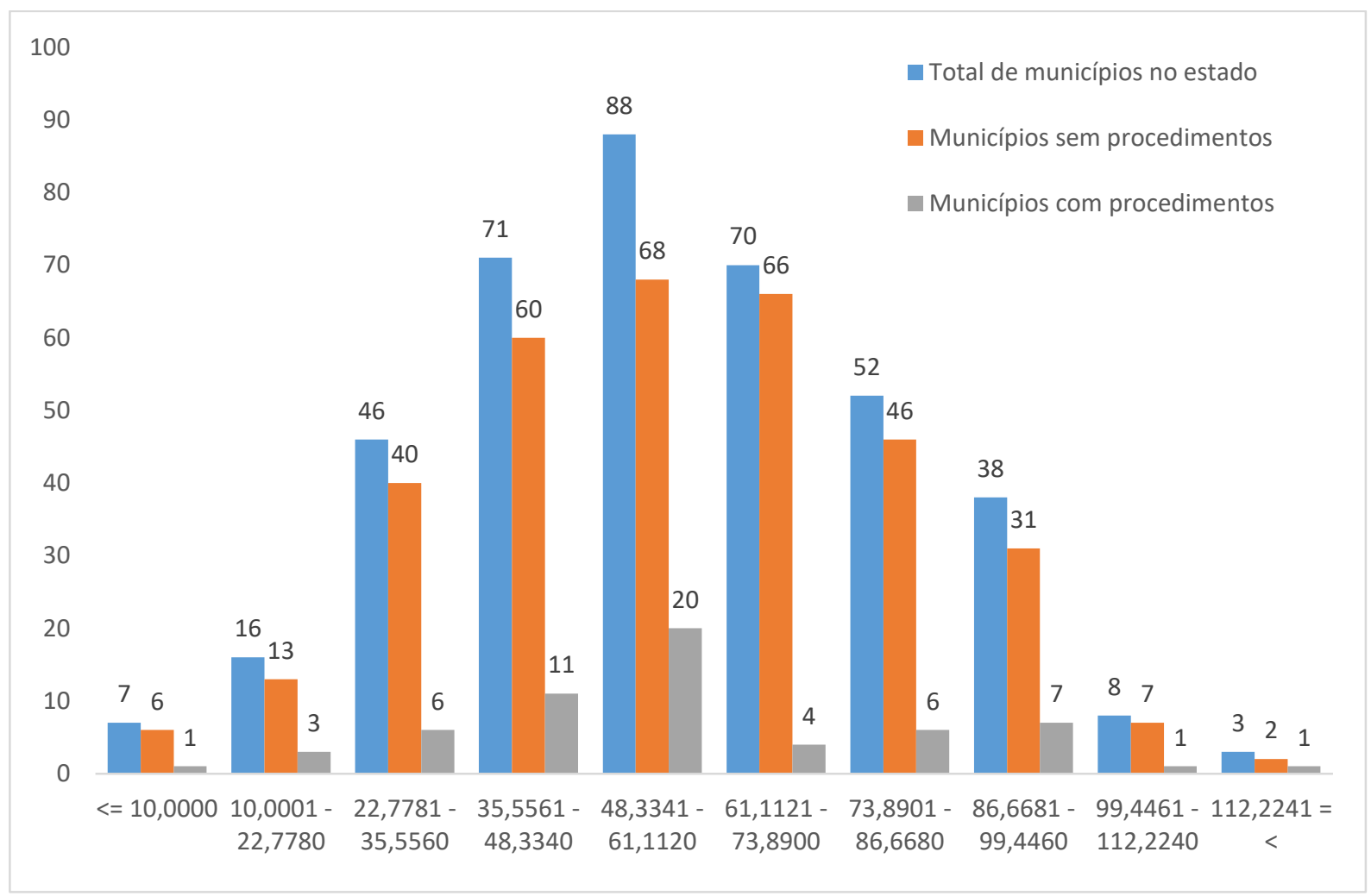

Fonte: Organizado a partir a partir dos dados da pesquisa, microdados do Censo escolar (Banco de matrículas, 2010) e dados populacionais Censo IBGE (2010).

Desse modo, parece haver certa relação entre o baixo atendimento na El e a existência das medidas coletivas analisadas, corroborando a ideia de que possam estar relacionadas à demanda organizada da população, em havendo carência de atendimento. Entretanto, quando as faixas de atendimento são desagregadas por creche e pré-escola, tal relação não aparece no caso do atendimento em pré-escola. No caso do atendimento em creche vemos uma concentração nas faixas mais baixas 


\section{Fism

ISSN: 1984-6444 | http://dx.doi.org/10.5902/1984644443035

publicização de listas de espera e dos critérios de priorização para concessão de vagas. No caso específico de Pato Branco, ainda, percebeu-se efeitos na ampliação da previsão orçamentária para investimento na EI (SILVEIRA et al., 2020).

Estas breves considerações indicam a variabilidade dos efeitos da judicialização da El no âmbito dos municípios e da gestão educacional, sugerindo que futuros trabalhos em contextos distintos possam ampliar tal entendimento. Mais além, pesquisas que analisem os efeitos da exigibilidade do direito à El no cotidiano escolar poderão esclarecer os efeitos deste fenômeno para além do âmbito da gestão.

\section{Considerações finais}

O caso paranaense demonstra um contexto de incidência do MP na exigibilidade do direito à El, induzida pela atuação do Caopcae/Educação. Tal incidência não se dá de modo uniforme em todo o estado, mas sua distribuição temporal mostra que há relação com o projeto estratégico empreendido pelo referido centro. Assim, nota-se que a judicialização da El no estado do Paraná por meio de medidas coletivas tem se dado, no caso pesquisado, exclusivamente por meio da atuação do MP, ainda que não da mesma maneira em todas as comarcas, mas com maior incidência em municípios não tão pequenos, com maior taxa de urbanização e renda média. Percebe-se, ainda, uma ampliação desta demanda temporalmente, ocorrendo um maior número de medidas judiciais nos últimos anos - o que pode estar relacionado ao prazo final do projeto estratégico mencionado acima, bem como ao prazo para cumprimento da EC 59/2009.

Percebe-se que os promotores de justiça têm empenhado maiores esforços em municípios que são sede de comarcas e que compõe entrâncias intermediárias ou finais. Por outro lado, tal atuação parece ter certa relação com baixas taxas de atendimento na etapa, o que pode indicar diálogo com as necessidades e demandas da população local. Este achado indica a necessidade de pesquisas que discutam como tem se dado a atuação do MP localmente, identificando se tal diálogo com a população tem efetivamente ocorrido. 


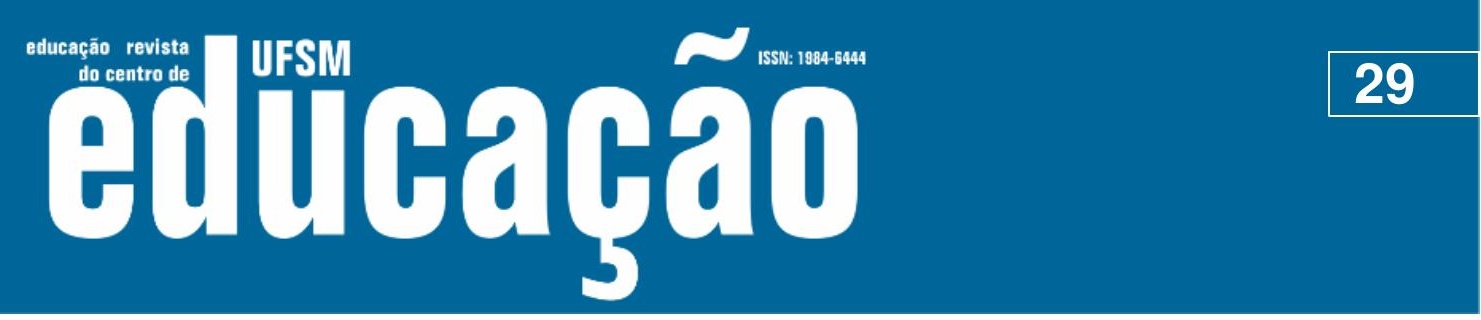

ISSN: 1984-6444 | http://dx.doi.org/10.5902/1984644443035

Ainda que a análise do conteúdo dos procedimentos não esteja no escopo deste artigo, as demandas da população local podem estar representadas nas amplas variações de conteúdo entre as diferentes comarcas, o que também pode estar relacionado ao perfil de atuação do promotor de justiça. Tal constatação remete à reflexão de Silva (2001), quando indica uma relevância significativa do perfil de cada promotor de justiça, havendo aqueles que se caracterizam por maior diálogo com a comunidade local e o poder público.

A literatura sobre o tema da judicialização da política (TATE; VALLINDER, 1995) delineia fatores que facilitam esse fenômeno: democracia, separação de poderes, reconhecimento formal de direitos; consciência dos meios judiciais pelos grupos de interesses e pelos partidos de oposição na realização de seus objetivos, inefetividade das instituições majoritárias; incapacidade das instituições em dar provimento às demandas sociais, delegando às cortes a tomada de decisão em determinadas áreas da política. Ao analisar o contexto de judicialização da El - em específico das medidas coletivas no estado do Paraná e não necessariamente refletindo a realidade do Brasil como um todo - cabe destacar que algumas variáveis institucionais do sistema de justiça, inclusive do perfil individual dos Promotores de Justiça, consolidam a existência deste processo, que não se encontra presente em todos os municípios, estando excluídos, principalmente, municípios menores que não são sede de comarca, não possuindo promotores de justiça na localidade.

Portanto, ao analisar a expansão do processo de judicialização da educação pela via difusa ${ }^{12}$, no caso do estado do Paraná, destaca-se que as características municipais e, principalmente, as características institucionais do sistema de justiça no município contribuem para a existência deste fenômeno. Indica-se, assim, que a utilização do Judiciário como uma arena relevante no questionamento de políticas educacionais possivelmente não é algo generalizado e acessível em todo o contexto brasileiro, ou em todos os casos em que haja violação do direito à educação. Mais além, os efeitos que esse fenômeno gera na administração pública são diversos. Desse modo, se mostra relevante considerar de que maneira tal processo possa estar refletindo ou amplificando desigualdades educacionais ou de acesso à justiça entre regiões e municípios. 


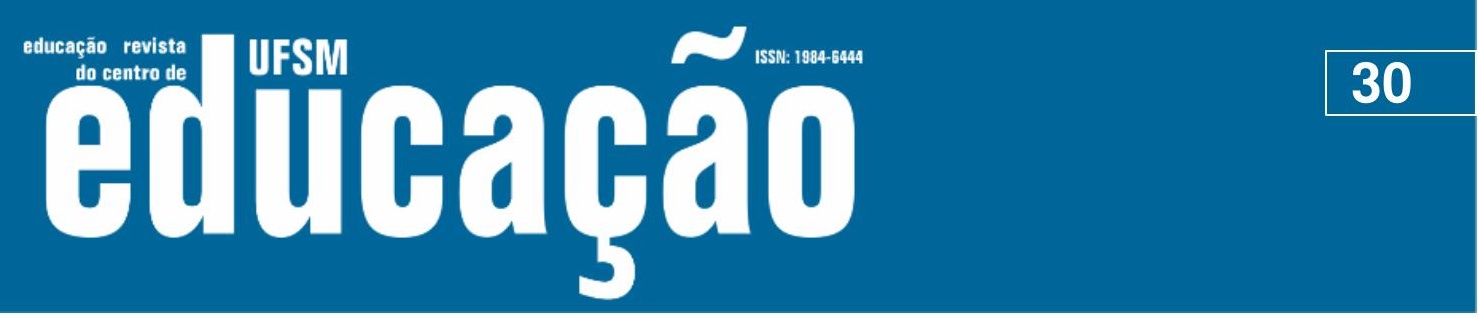

ISSN: 1984-6444 | http://dx.doi.org/10.5902/1984644443035

\section{Referências}

ARANTES, Rogério Bastos. Direito e política: o Ministério Público e a defesa dos direitos coletivos. Rev. bras. Ci. Soc. [online]. 1999, vol.14, n.39, p. 83-102.

ARANTES, Paulo Henrique de Oliveira. Perspectivas de Atuação do Ministério Público nas Lutas pela Efetividade do Direito à Educação Infantil. Dissertação (Mestrado Acadêmico em Direito). Universidade Est. Paulista Júlio de Mesquita Filho, UNESP, 2011.

BRASIL. Recomendação no 30, de 22 de setembro de 2015. Dispõe sobre a atuação do Ministério Público na garantia à Educação Infantil. Portal do Conselho Nacional do Ministério Público, Brasília-DF, 22 de setembro de 2015. Disponível em: http://www.cnmp.mp.br/portal_2015/images/Normas/Recomendacoes/Recomenda\% C3\%A7\%C3\%A3o_30-2015_1.pdf. Acesso em: 19.10.2016.

BRASIL. Instituto Nacional de Estudos e Pesquisas Educacionais Anísio Teixeira. Relatório do 20 Ciclo de Monitoramento das Metas do Plano Nacional de Educação - 2018. Brasília, DF: Inep, 2018.

CURY, Carlos Roberto Jamil. A Educação Infantil como direito. In: BRASIL, Ministério da Educação e do Desporto. Subsídios para credenciamento e funcionamento de instituições de Educação Infantil. Volume II. Brasília: MEC, 1998.

CURY, Carlos Roberto Jamil; FERREIRA, Luiz Antonio Miguel. Justiciabilidade no campo da educação. RBPAE, Goiânia, v. 26, n. 1, p.75-103, jan. 2010.

DAMASCO, Denise Gisele de Britto. 0 direito à educação: a atuação das Promotorias de Justiça e de defesa da educação do Ministério Público do Distrito Federal e Territórios, entre 2001 e 2007. Dissertação (Mestrado em Educação) Universidade de Brasília, 2008.

DUARTE, Clarice Seixas. Direito público subjetivo e políticas educacionais. São Paulo em Perspectiva. São Paulo, v. 18, n. 2, 2004. p. 113-118.

FELDMAN, Marina; SILVEIRA, Adriana A. Dragone. A pressão para expansão do direito à educação infantil por meio de Termos de Ajustamento de Conduta.

Educação \& Sociedade (Impresso), v. 39, p. 1023-1040, 2018.

GONÇALVES, Aline de Barros Vidal. A exigibilidade de vagas na educação infantil e a atuação do sistema de justiça no município de Colombo. Curitiba: Universidade Federal do Paraná, 2017. 26 p. Relatório final de iniciação científica. 


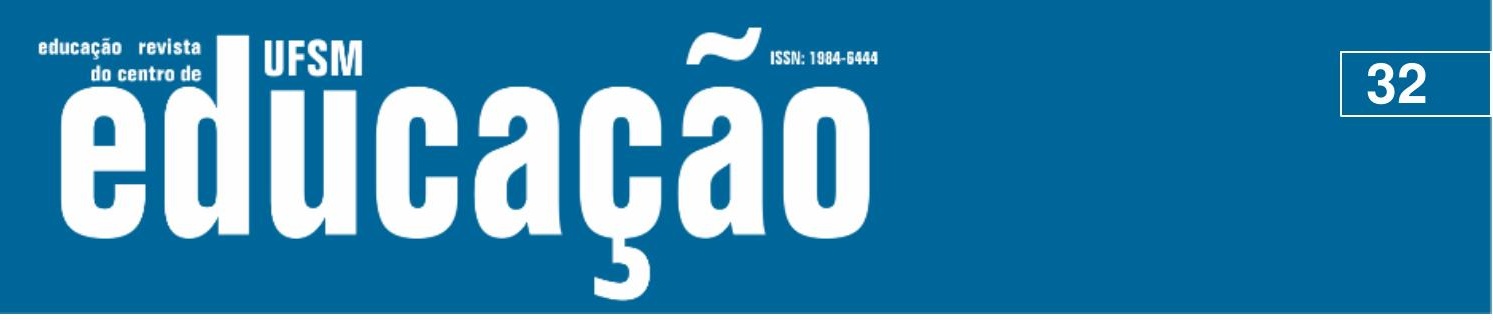

ISSN: 1984-6444 | http://dx.doi.org/10.5902/1984644443035

SILVEIRA, Adriana Aparecida Dragone. Direito à Educação e o MP: Uma análise da atuação de duas Promotorias de Justiça da Infância e Juventude do interior paulista. Dissertação (Mestrado) - Faculdade de Educação da Universidade de São Paulo, SP, 2006.

SILVEIRA, Adriana Aparecida Dragone. Conflitos e consensos na exigibilidade judicial do direito à educação básica. Educação \& Sociedade, v. 34, n. 123, 2013.

SILVEIRA, Adriana Aparecida Dragone. Exigibilidade do direito à educação infantil: uma análise da jurisprudência. In. SILVEIRA, Adriana Dragone; GOUVEIA, Andréa Barbosa; SOUZA, Ângelo Ricardo de. Conversas sobre políticas educacionais. Curitiba: Appris, 2014. p. 167-188.

SILVEIRA, Adriana Dragone. Judicialização da política educacional: uma análise da atuação do Ministério Público e do Tribunal de Justiça do Paraná. Educação em Perspectiva (Online), v. 8, p. 1-18, 2018.

SILVEIRA, Adriana Aparecida Dragone; XIMENES, Salomão Barros; OLIVEIRA, Vanessa Eilas; CRUZ, Silvia Helena Vieira; BORTOLLOTI, Nadja. Efeitos da judicialização da educação infantil em diferentes contextos subnacionais. Cadernos de Pesquisa, São Paulo, v. 50, n. 157, p. 718-737, jul.-set. 2020.

SOUSA SANTOS, Boaventura. Para uma revolução democrática da justiça. São Paulo: Cortez, 2007.

SOUSA SANTOS, Boaventura et al. Os tribunais nas sociedades contemporâneas: o caso português. Porto: Edições Afrontamento, 1996.

TAPOROSKY, Barbara Cristina Hanauer. O controle judicial da qualidade da oferta da educação infantil: um estudo das ações coletivas nos tribunais de justiça do Brasil (2005-2016). Dissertação (Mestrado em Educação) - Setor de Educação da Universidade Federal do Paraná, Curitiba, 2017.

TAPOROSKY, Barbara Cristina Hanauer; SILVEIRA, Adriana A. Dragone. A qualidade da educação infantil como objeto de análise nas decisões judiciais. Educação em Revista (online), v. 34, p. e189508, 2018.

TATE, Neal; VALLINDER; Torbjorn. The Global Expansion of Judicial Power. New York: New York University Press, 1995.

VICTOR, Rodrigo Albuquerque de. Judicialização de Políticas Públicas para a Educação Infantil: características, limites e ferramentas para um controle judicial legítimo. São Paulo: Saraiva, 2011. 


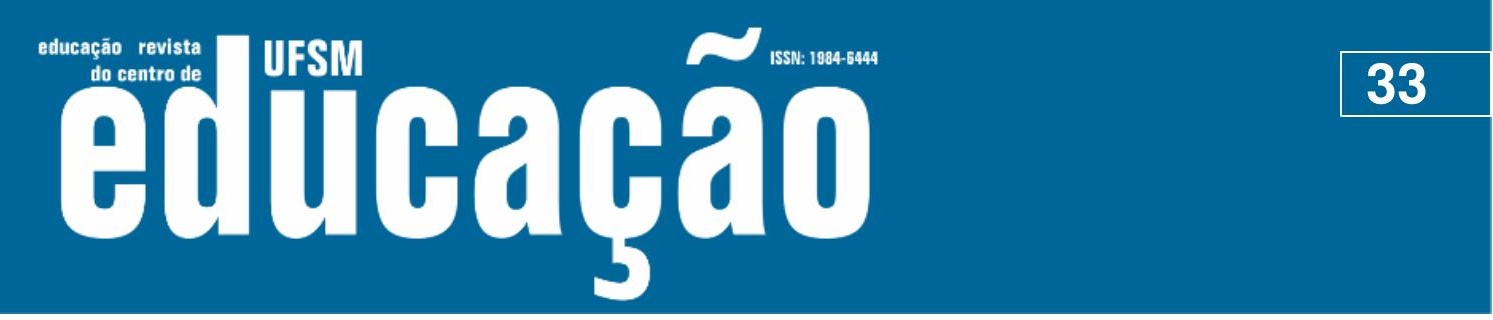

ISSN: 1984-6444 | http://dx.doi.org/10.5902/1984644443035

XIMENES, Salomão Barros; SILVEIRA, Adriana Dragone. Judicialização da Educação[:caracterização e crítica. In: Vanessa Elias de Oliveira (Org.). Judicialização de Políticas Públicas no Brasil. Rio de Janeiro: Fio Cruz, 2019.

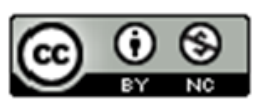

This work is licensed under a Creative Commons Attribution-NonCommercial 4.0 International (CC BY-NC 4.0)

\section{Notas}

${ }^{1}$ Elaborado pelo Laboratório de Dados Educacionais a partir da Pesquisa Nacional por Amostra de Domicílios (PNAD), arquivo Pessoas, IBGE (2015).

2 Os dados coletados referentes às medidas extrajudiciais foram atualizados até maio de 2016 e os referentes às ações judiciais até julho de 2016.

${ }^{3}$ O Caopcae/Educação, criado pela Procuradoria Geral de Justiça do estado do Paraná em 2002, funciona como órgão de apoio aos promotores de justiça do MP paranaense para questões específicas relacionadas à educação.

${ }^{4}$ Com prazo de encerramento no ano de 2016, o mesmo prazo da EC 59/2009, o projeto se encontrava em processo de finalização institucional até 2018.

5 Dados estatísticos elaborados e disponibilizados pela Subprocuradoria-Geral de Justiça para Assuntos de Planejamento Institucional (SUBPLAN) do MP paranaense.

${ }^{6}$ Segundo Gonçalves (2017), as ACPs ajuizadas pelo MP no município de Colombo visavam conseguir vagas para um número reduzido de crianças, todas nominadas nas ações, visando não inviabilizar o pedido ao apresentar requerimento de vagas para um número indeterminado de crianças.

7 Conforme a Lei 7.347 de 24 de julho de 1985, são legitimados a propor ACPs, além do MP, a Defensoria Pública, a União, os Estados, o Distrito Federal e os Municípios, autarquias, empresas públicas e sociedades de economia mista, bem como as associações que cumpram os requisitos legais.

8 Classificação de porte populacional a partir de IBGE (2010). Municípios de Pequeno Porte 1: até 20.000 habitantes; Município de Pequeno Porte 2: de 20.001 até 50.000 habitantes; Município de Médio Porte: de 50.001 até 100.000 habitantes; Município de Grande Porte: de 100.001 até 900.000 habitantes.

${ }^{9}$ Nos casos em que o município não é sede de comarca, considerou-se a entrância da comarca à qual o mesmo está vinculado.

10 Para a identificação dos municípios que compõem cada comarca, utilizou-se o código de organização e divisão judiciárias do TJPR. Contudo, estão indicados no documento apenas 391 municípios, o que diverge dos 399 existentes no estado. Tendo em vista que se trata da fonte oficial em relação à divisão judiciária do estado, mantiveram-se os dados constantes no documento.

${ }^{11}$ No estado do Paraná, os serviços judiciários são divididos por comarcas. Contudo, há quatro delas que são subdivididas em foros. Neste caso, há nas cidades sede de foros os serviços judiciários disponíveis, contudo estão administrativamente subordinadas às sedes de comarcas. Para fins do gráfico 8, consideramos foros como sede de comarcas, já que a relevância do dado está na existência de serviços judiciários na localidade. 


\section{Lew \\ ISSN: 1984-6444

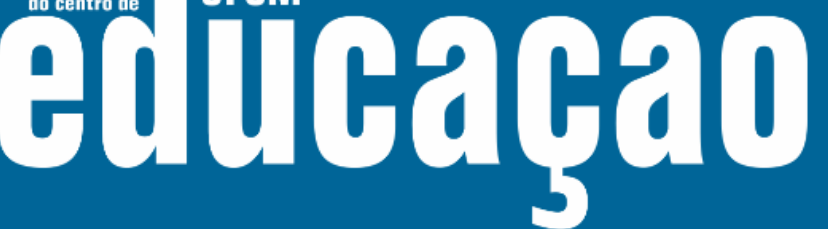

ISSN: 1984-6444 | http://dx.doi.org/10.5902/1984644443035

12 Via difusa refere-se a ações iniciadas pelo questionamento do direito através da justiça de primeira instância em um caso concreto, e não pela via concentrada, que resulta no questionamento da constitucionalidade de lei ou ato normativo, como por meio de Ação Direta de Inconstitucionalidade e/ou Ação Declaratória de Constitucionalidade. 